Results: The levels of BAFF were significantly higher in group $3(0.88 \pm 0.19$ $\mathrm{ng} / \mathrm{ml})$ compared with group $1(0.68 \pm 0.13 \mathrm{ng} / \mathrm{ml}, \mathrm{p}<0.05)$, but did not distinguish from the group $2(0.90 \pm 0.35)$. There were not significant differences in ESR between groups. ROC analysis indicated that the AUC for ESR is $0.63 \pm 0.10$ $(p=0.17)$ and for BAFF $-0.72 \pm 0.12(p<0.05)$, which indicates fair capacity for BAFF differentiate groups of pts with low activity or remission of SNV and pts with severe SNV (sensitivity - $61.5 \%$, specificity - $88.9 \%$ ), while it was poor for ESR (sensitivity - $85.7 \%$, specificity - 46.4\%).

Conclusions: There are significant differences in levels of BAFF between pts with $B V A S \geq 24$ and pts with $B V A S \leq 11$. According to ROC analysis evaluation of serum BAFF level distinguishes pts with active SNV from pts with low activity or remission better than determination of ESR.

Disclosure of Interest: None declared

DOI: 10.1136/annrheumdis-2017-eular.2200

\section{FRI0341 CLINICO-PATHOLOGICAL DISCREPANCIES AND CAUSES OF DEATH IN TAKAYASU ARTERITIS: A RETROSPECTIVE ANALYSIS OF 60 FATAL CASES}

O. Zimba ${ }^{1}$, M. Bagriy ${ }^{2}{ }^{1}$ the Department of Internal Medicine, Danylo Halytsky Lviv National Medical University, Lviv; ${ }^{2}$ Department of Pathological Anatomy, Ivano-Frankivsk National Medical University, Ivano-Frankivsk, Ukraine

Background: Takayasu arteritis (TA) may present with a wide spectrum of symptoms common to other diseases leading to delayed or missed diagnosis. Objectives: To investigate the rate of undiagnosed clinically cases of TA, and provide a detailed analysis of the wrong diagnoses and the underlying causes of death.

Methods: A retrospective clinicopathological analysis of sixty autopsy cases (52 males and 8 females aged 18 to 45 years) of TA over period of 11 years have been performed. The median age at disease onset was 25, 7 years.

Results: In 33 cases (55\%), TA was not diagnosed during the clinical stages but only in autopsy. The most common incorrect clinical diagnosis was atherosclerosis of the aorta and its branches (celiac trunk, renal, mesenteric and iliac arteries) that has misdiagnosed in 14 cases $(42.4 \%)$ of TA. TA was misdiagnosed as myocardial infarction/ischaemic heart disease in $5(15.1 \%)$, perforated peptic ulcer in $3(9.1 \%)$, polyarteritis nodosa in $3(9.1 \%)$, and infective endocarditis in 2 cases $(6.1 \%)$. There were other discrepancies in 6 cases $(18.2 \%)$; in these cases, cerebral haemorrhage, rheumatic heart disease, pulmonary embolism, pheochromocytoma, chronic glomerulonephritis and lung cancer were the wrong clinical diagnoses. The leading position in the mortality structure due to TA belongs to septic shock that observed in 19 cases $(31.7 \%)$ due to peritonitis/acute abdomen caused by mesenteric artery occlusion with subsequent intestinal necrosis in $12(63.1 \%)$, lower limb gangrene in $6(31.6 \%)$, and prosthetic aortic graft infection in $1(5.3 \%)$. The second-leading cause of death was acute heart failure due to myocardial infarction, and renovascular arterial hypertension (25\%). The third common cause of death was haemorrhagic shock in 14 cases $(23.3 \%)$. The acute bleeding was caused by ruptured aortic aneurysm in abdominal part in 6 cases $(42.8 \%)$ and ascending aorta with cardiac tamponade in $4(28.6 \%)$. In 2 cases $(14.3 \%)$, the source of hemorrhage was ulcers of gastrointestinal tract. The surgery has complicated by lethal bleeding in 2 cases (14.3\%). In other patients, causes of death were cerebral haemorrhage in $6(10 \%)$, renal failure in $3(5 \%)$, respiratory failure in $1(1.7 \%)$, and revascularization syndrome in $1(1.7 \%)$. In one case, TA coexisted with scleroma of larynx, and asphyxia was direct cause of death.

Conclusions: Our date show a high number of cases of TA (55\%) that were identified at autopsy but were not diagnosed clinically. It can be assumed that aortic atherosclerosis, myocardial infarction/ischaemic heart disease were the most common wrong diagnoses in TA. The leading causes of death in TA are septic shock, acute heart failure, and haemorrhagic shock. In addition, it should be noted that in our series of autopsy cases of TA, males $(86,7 \%)$ were most frequently affected compared with results other investigations. Interestingly, that the correct diagnosis of TA was established before death in all females' cases. It seems to be a trend to miss the clinical diagnosis of TA in male patients.

Disclosure of Interest: None declared

DOI: 10.1136/annrheumdis-2017-eular.6182

\section{FRI0342 DISTRIBUTION OF VASCULITIDES IN EASTERN MEDITERRANEAN: RESULTS OF A PROSPECTIVE COHORT}

O. Karadag, A. Erden, E.D. Batu, E. Bilgin, A.O. Uyaroglu, E. Seyhoglu, E.C. Bolek, E. Firat, H.E. Sonmez, S.Z. Arici, L. Kilic, A. Akdogan, S.A. Bilgen, S. Kiraz, I. Ertenli, S. Ozen. Hacettepe University Vasculitis Center, Ankara, Turkey

Background: The ethnic and geographical differences have been commented on, mainly from European data. We lack large data sets from the eastern part of Europe.

Objectives: This study is aimed to present the distribution of vasculitides in the Pediatric and Adult Vasculitis patient groups.

Methods: Hacettepe University is one of the main referral centers in the capital of Turkey, serving approximately 470,000 adult and pediatric patients/a year. Hacettepe University Vasculitis Centre (HUVAC) was established to organize a prospective cohort in 2014. All patients starting from October 2014 have been recorded to the database. Additionally electronic patient recording database between October 2014-December 2016 was searched for the patients having any of the 10th revision of the International Statistical Classification of Diseases (ICD)-10 code for the particular vasculitis. The study group of Hacettepe University Vasculitis Centre (HUVAC) re-evaluated the ascertained patients' hospital records to review their diagnosis according to the 2012 revised Chapel Hill nomenclature criteria.

Results: A total of 1196 patients had been newly followed in this period. 271 (22.7\%) of them were pediatric patients and $31.8 \%$ of them were newly diagnosed. The leading vasculitis among adult patients was Behcet's Disease whereas in pediatric patients it was HSP/lgA Vasculitis (Table). Granulomatous polyangiitis was the most common small vessel vasculitis in adults. Takayasu arteritis was more frequent than giant cell arteritis among the adult patients. There was a female predominance in patients with large vessel vasculitis.

During prospective follow up, $22(1.9 \%)$ patients deceased; 7 due to the primary disease, 6 due to infections, 7 due to cardio and cerebrovascular diseases.

Table, Distribution and gender of Adult and Paediatric Vasculitides Patients

\begin{tabular}{|c|c|c|}
\hline \multicolumn{3}{|l|}{ Adult Patients $(\mathrm{n}=925)$} \\
\hline Type & Frequency, $\%$ & Female, $\%$ \\
\hline Behcet's Disease & 50.5 & 53.7 \\
\hline ANCA Associated Vasculitis & 11.9 & 46.4 \\
\hline - $\quad$ GPA & 8.9 & 47.9 \\
\hline EGPA & 2.2 & 52.3 \\
\hline - MPA & 0.8 & 57.1 \\
\hline Takayasu's Arteritis & 10.7 & 90 \\
\hline IgA Vasculitis & 4.3 & 47.5 \\
\hline Giant Cell Arteritis & 3.8 & 71.4 \\
\hline Cutaneous Vasculitis & 3.2 & 70 \\
\hline Polvarteritis Nodosa & 3.1 & 44.8 \\
\hline IgG4 Related Disease & 2.8 & 48.2 \\
\hline CTD-Secondary Vasculitis & 2.3 & 71.4 \\
\hline Polimyalgia Rheumatica & 2.2 & 95 \\
\hline Primary CNS Vasculitis & 0.8 & 42.8 \\
\hline Isolated Aortitis & 0.8 & 50 \\
\hline Cryoglobulinemic Vasculitis & 0.4 & 25 \\
\hline Others & 3.2 & 57.3 \\
\hline \multicolumn{3}{|l|}{ Paediatric patients $(n=271)$} \\
\hline Type & Frequency,\% & Female, $\%$ \\
\hline IgA Vasculitis & 46.5 & \begin{tabular}{|l|}
45.6 \\
\end{tabular} \\
\hline Behcet's Disease & 22.5 & 45.9 \\
\hline Kawasaki Disease & 17.3 & 45.6 \\
\hline Polyarteritis Nodosa & 3.7 & 50.0 \\
\hline Takayasu's.Arteritis & 2.6 & 100 \\
\hline ANCA Associated Vasculitis & 1.5 & 75 \\
\hline Vasculopathies (SAVI, DADA2) & 1.5 & 37.5 \\
\hline Others & 4.4 & 52.3 \\
\hline
\end{tabular}

Conclusions: Behcet's Disease is the most frequent vasculitis in Turkey and more than half of the patients had organ/system involvements. GPA is the most common small vessel vasculitis whereas Microscopic polyangiitis is very rare. Among children Kawasaki was less and Behçet's disease markedly more when compared to Western European figures. Even though this study is a single-center one, the number of annual admitted patients of our hospital along with more than 2 years-prospective recruitment, reflects the true burden of vasculitides in Turkey, at the cross-roads between Europe and Middle East.

Disclosure of Interest: None declared

DOI: 10.1136/annrheumdis-2017-eular.5322

\section{FRI0343 COGNITIVE DISORDERS IN BEHCCET'S DISEASE: SOME CLINICAL AND PATHOGENESIS RELATIONS}

P. Ovcharov $^{1}$, T. Lisitsyna ${ }^{1}$, D. Veltishchev ${ }^{2}$, D. Burenchev ${ }^{3}$, D. Ishchenko ${ }^{2}$ ${ }^{\text {O. Seravina }}{ }^{2}$, O. Kovalevskaya ${ }^{2}$, Z. Alekberova ${ }^{1}$, E. Nasonov ${ }^{1} .{ }^{1}$ Nasonova Research Institute of Rheumatology, Moscow, Russia; ${ }^{2}$ Moscow Research Institute of Psychiatry; ${ }^{3}$ City policlinic No. 12 Moscow Department of Health, Moscow, Russian Federation

Background: the cognitive disorders (CD) is a special psychopathological problem for Behçet's Disease (BD) patients. The causes of CD aren't enough investigated. Anxiety/depressive disorders and primary neural parenchymal lesions due to BD usually related to $C D$ in these patients.

Objectives: to determine the prevalence of $\mathrm{CD}$ in $\mathrm{BD}$ patients and its associations with some clinical and magnetic resonance imaging (MRI) scan features.

Methods: the investigation has been realized in accordance with the interdisciplinary program "Stress factors and mental disorders in immune-mediated inflammatory rheumatic diseases".

$106 \mathrm{BD}$ patients were enrolled in the study. The majority of patients were men $(72,6 \%)$, natives of the North Caucasus $(51,9 \%)$, with mean age $(M \pm m) 33,3 \pm 0,98$ years. All the patients met the criteria of the International Study Group for BD (1990) classification. The disease activity was assessed by scoring system BDCAF.

$\mathrm{CD}$ were diagnosed with psychology and neuropsychology methods. Mental disorders (MD) were diagnosed by psychiatrist in accordance with the ICD-10 in semi-structured interview. The severity of depression and anxiety was evaluated 